\title{
MODELLING THE PROCESS OF HEAT TRANSFER THROUGH PARTS OF AGRICULTURAL MACHINERY IN CASE OF GAS THERMAL APPLICATION OF SELF- FLUXING POWDERS
}

\author{
Evgeniy Pukhov, Kirill Zagoruyko, Ivan Schegolev \\ Voronezh State Agrarian University named after Emperor Peter the Great, Russia \\ puma231@yandex.ru, kir835@yandex.ru, ivan-shheglev2863@rambler.ru
}

\begin{abstract}
In the course of operation of agricultural machinery, the need for repair works for the replacement or restoration of critical parts occurs. High price of, for example, the crankshaft or camshaft for tractors, harvesters, and cars makes agricultural producers need to develop economically viable resource-saving technologies for the restoration of critical parts. Active development of technology for hardening parts in mechanical engineering has led to the creation of a whole complex of metal-containing powders. At the same time, the possibility of their use in agriculture remains poorly understood. In this study, it is proposed to use the technology of applying selffluxing powders using a gas flame. However, it requires the development of a control and quality control system for the resulting coatings (elimination of overheating of the part, the formation of the preset thickness of the resulting coating), taking into account the volumetric-geometric and physical-chemical parameters of the restored or hardened surface. Quality control of the coatings is the selection of optimal technological parameters that affect the final performance, and changing them according to the given procedure, or keeping them in the stable condition. Adjustable parameters are the distance from the surface of the part to the flame nozzle, when applying self-fluxing powder, and the peripheral speed of the part. Mathematical modeling of the process of heat distribution in the surface layer of a part during coating allows substantiating these parameters. The results obtained in the modeling process (peripheral speed of the part, distance from the part surface to the flame nozzle, and the direction of movement of the burner relative to the part) make it possible to substantiate the technological modes of coating that satisfy the conditions for eliminating overheating of the part and the formation of a uniform coating layer(s) of a given thickness.
\end{abstract}

Keywords: agricultural machinery, restoration, hardening, crankshaft, heat transfer, modeling.

\section{Introduction}

Under the conditions of agricultural production, the cost of restoring parts for the piece and smallscale production is of no small importance. Analysis of the technologies for the restoration and hardening of critical machine parts, including agricultural machinery (crankshafts and camshafts, exteriors), shows the tendency to use carbide self-fluxing powders in the technological processes [112]. Recently, many compositions were created on the basis of iron, nickel, and cobalt. Such a variety has appeared due to the development of $3 \mathrm{~d}$ prototyping technology, which is used to quickly create parts, including metal ones.

The designing of low-cost and generally accessible recovery technologies using self-fluxing powders in agriculture remains an unsolved task. At present, the opportunities for using carbide selffluxing powders in agriculture and ensuring the strength characteristics of coatings have not been fully studied.

One of the economically and technologically promising technologies for surface restoration and protection against corrosion of agricultural machinery parts subject to wear can be attributed to the thermal application of self-fluxing powders (thermal coating). In recent years, research work has been carried out in Russia and abroad in order to create such a technology. In particular, studies are being performed to determine the optimal application regimes.

The properties and qualities of the resulting coatings are determined by both the physicochemical properties of the powder materials $[12 ; 13]$ and the characteristics of the devices, the kinematic process diagram, and application conditions $[1 ; 2 ; 5 ; 7 ; 12 ; 13]$. The quality of the resulting coatings greatly depends on the thermal processes that occur during the interaction of heated powder particles with the restored surface of the part and are determined by the choice of optimal control parameters [6; 14-19].

Experimental studies to determine the optimal application conditions require a long time to obtain reliable results. Mathematical modeling of the thermal cladding process allows to process a larger amount of data, obtain the appropriate parameters for specific production conditions and further develop a control program with lower costs. 


\section{Materials and methods}

The designed model needed to simulate the shape of the part, and also because of the movement of the heating zone along the surface of the part, it was necessary to take into account the dynamics of thermal processes from the center to the boundaries of the zone. Moreover, it was necessary to present the interaction of various process media - plated material, material of the restored part, a jet of burning gas, and air surrounding it. To do this, the investigated space in the shape of the part is represented discretely in the model as a set of points, which allowed the use of algorithms and the numerical simulation method.

To determine the relationship between the values, methods of mathematical physics were used, considering the process for an elementary volume of the substance over an infinitesimal period of time (discretely). Such a dependence is described by the differential heat equation (Fourier equation), which establishes the relationship between temporal and spatial changes in temperature at any point in the volume. Within the boundaries of an infinitesimal period of time, it becomes possible to neglect the change in some values characterizing the process. While deriving the Fourier equation, the following assumptions are accepted: - the physical values $\lambda, c_{p}$ and $\rho$ are constant, internal heat sources are absent, and the energy conservation law is applicable (the difference between the amount of heat entering the investigated three-dimensional space during the time $d \tau$ and leaving it during the same time is spent on changing the internal energy of the volume under consideration). As a result, we arrive at the following heat equation for the three-dimensional model:

$$
\frac{\partial}{\partial t} T(\vec{r}, t)=(\nabla, \chi(\vec{r}, t) \nabla T(\vec{r}, t))+Q(\vec{r}, t),
$$

where $\vec{r}$ - radius vector and $x, y, z$ - Cartesian coordinates of the studied space point;

$t$ - research timepoint;

$i, j, k$ - unit vectors in Cartesian space;

$T(\vec{r}, t)$ - temperature distribution in space and its change in time;

$\nabla=\frac{\partial}{\partial x} \vec{i}+\frac{\partial}{\partial y} \vec{j}+\frac{\partial}{\partial z} \vec{k}$ - vector differential operator nabla (Hamilton), summands of which are local derivatives in three coordinates;

$\chi(\vec{r}, t)$ - substance temperature conductivity coefficient (depends on the position in space and time);

$\nabla T(\vec{r}, t)$ - temperature gradient (vector directed along the normal line to the isothermal surface toward temperature growth and equal to the local derivative of the temperature at this direction);

$\nabla T(\vec{r}, t)$ - heat source field changing in time with the coating application using the studied method.

The temperature conductivity coefficient may be expressed through the heat conductivity coefficient $k$, heat capacity ratio $c$, and the mass density $\rho: \chi=k /(c \cdot \rho)$. In our case, we take into account the presence of two substances in the experiment: the metal of which the crankshaft is made, with the coefficient $\chi=0.25 \mathrm{~W} \cdot(\mathrm{m} \cdot \mathrm{K})^{-1}$ and the gas surrounding the shaft with the coefficient $\chi=0.026 \mathrm{~W} \cdot(\mathrm{m} \cdot \mathrm{K})^{-1}$.

Simulation is performed with the use of the grid method: the temperature propagation in the part of a given shape and the subsequent appearance of the coating of the material on the surface of the part are reproduced. We represent each of the three dimensions of space in the form of a discrete rectangular grid with a step $=1 \mathrm{~mm}$. The number of such cells in each of the three spatial directions $X$, $Y, Z$ is 100 . Accordingly, the total number of cells is 1 million discrete points. Any grid node is bordered by six nodes, from which some heat transfer can occur, or to which heat transfer is carried out from the central node of Fig. 1.

Immediately at the first moment of the cladding process, all grid nodes have the same ambient temperature. In our experiment, this is the temperature of laboratory air $+22^{\circ} \mathrm{C}$. In the calculated model, the restored part is stationary. The heating zone moves around the part in the $x=0$ plane. 
a)

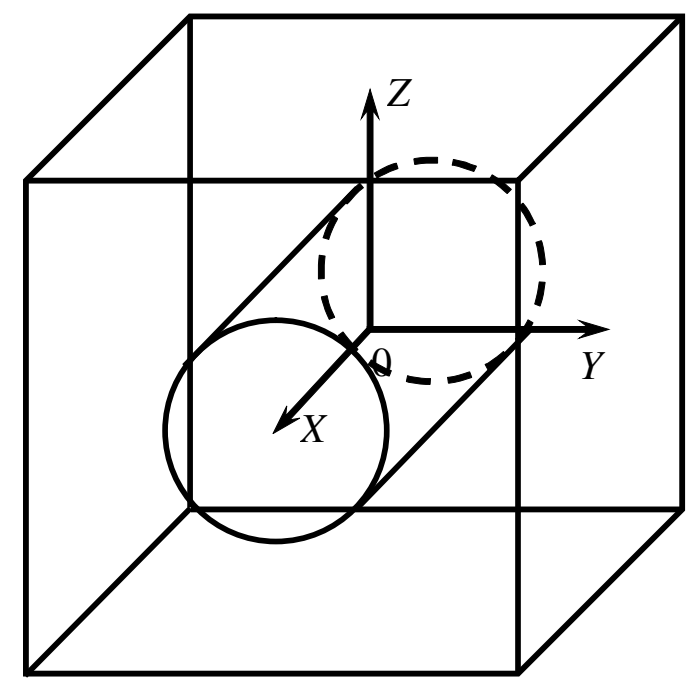

b)

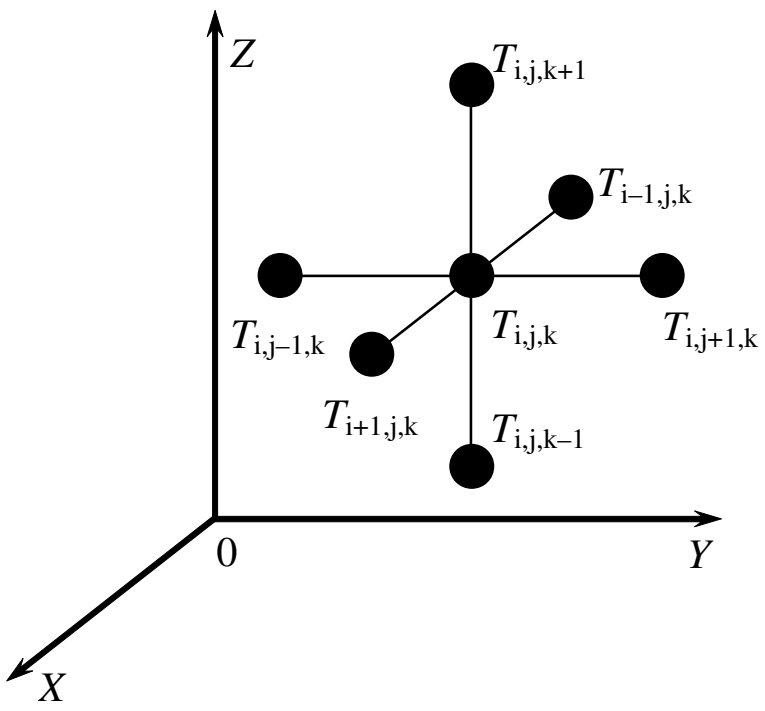

Fig. 1. Grid representation of the simulated space

With this representation, the dependence of the temperature $T_{i, j, k}$ for any node $(i, j, k)$ at each discrete step on the temperature of neighboring nodes through the Fourier equation can be written in the form:

$$
\begin{gathered}
\frac{\left(T_{i+1, j, k}-T_{i, j, k}\right)-\left(T_{i, j, k}-T_{i-1, j, k}\right)}{(\Delta x)^{2}}+\frac{\left(T_{i, j+1, k}-T_{i, j, k}\right)-\left(T_{i, j, k}-T_{i, j-1, k}\right)}{(\Delta y)^{2}}+\frac{\Delta T_{i, j, k}}{\Delta t}=\chi_{i, j, k} \\
\frac{\left(T_{i, j, k+1}-T_{i, j, k}\right)-\left(T_{i, j, k}-T_{i, j, k-1}\right)}{(\Delta z)^{2}}+Q_{i, j, k},
\end{gathered}
$$

where $\Delta t$ - sample timing;

$\Delta x=\Delta y=\Delta z=h-$ sample spacing;

$\chi$ - temperature conductivity coefficient;

$Q_{i, j, k}$ - heat input from the environment to a given cell.

Solving the equation (2) we get the final formula for the heat calculation

$$
\frac{T_{i, j, k}^{\tau+1}-T_{i, j, k}^{\tau}}{\Delta t}=\frac{\chi_{i, j, k}}{h^{2}}\left(T_{i+1, j, k}^{\tau}+T_{i-1, j, k}^{\tau}+T_{i, j+1, k}^{\tau}+T_{i, j-1, k}^{\tau}+T_{i, j, k+1}^{\tau}+T_{i, j, k-1}^{\tau}-6 \cdot T_{i, j, k}^{\tau}\right)+Q_{i, j, k},
$$

allowing the calculation of the temperature $T^{\tau+1}{ }_{i, j, k}$ for each cell $(i, j, k)$ for the next sample timing $\tau+1$ based on the current temperature $T^{\tau+1}{ }_{i, j, k}$, of the current integration step $\tau$.

\section{Results and discussion}

The construction of a model of heat distribution in the part, restored by thermal spraying of selffluxing powder, was carried out using a specially developed coating program for the crankshaft rod journal and main bearing journals. The results of the program are presented in Figure 2.

The subprogram displays on the projection screen of the part a graph of the temperature distribution along the axis of the crankshaft, as well as cartograms of the temperature distribution in the longitudinal and transverse sections of the part. The subprogram is applicable for crankshafts of various types and other parts of agricultural machines with pronounced axial symmetry.

A computer implementing the subprogram must have a processor of at least Pentium $3.0 \mathrm{GHz}$ and a RAM capacity of at least 4 GB. The operating system used is Windows 7 . The source code is written in the programming language Object Pascal in the integrated environment of Borland Delphi 7 and has a capacity of $12 \mathrm{~KB}$. 
The main technical limitations of the subprogram: the step of integrating differential equations is not more than 0.01 with a maximum size of the cube of the discretization of space not more than $1 \mathrm{~mm}$.

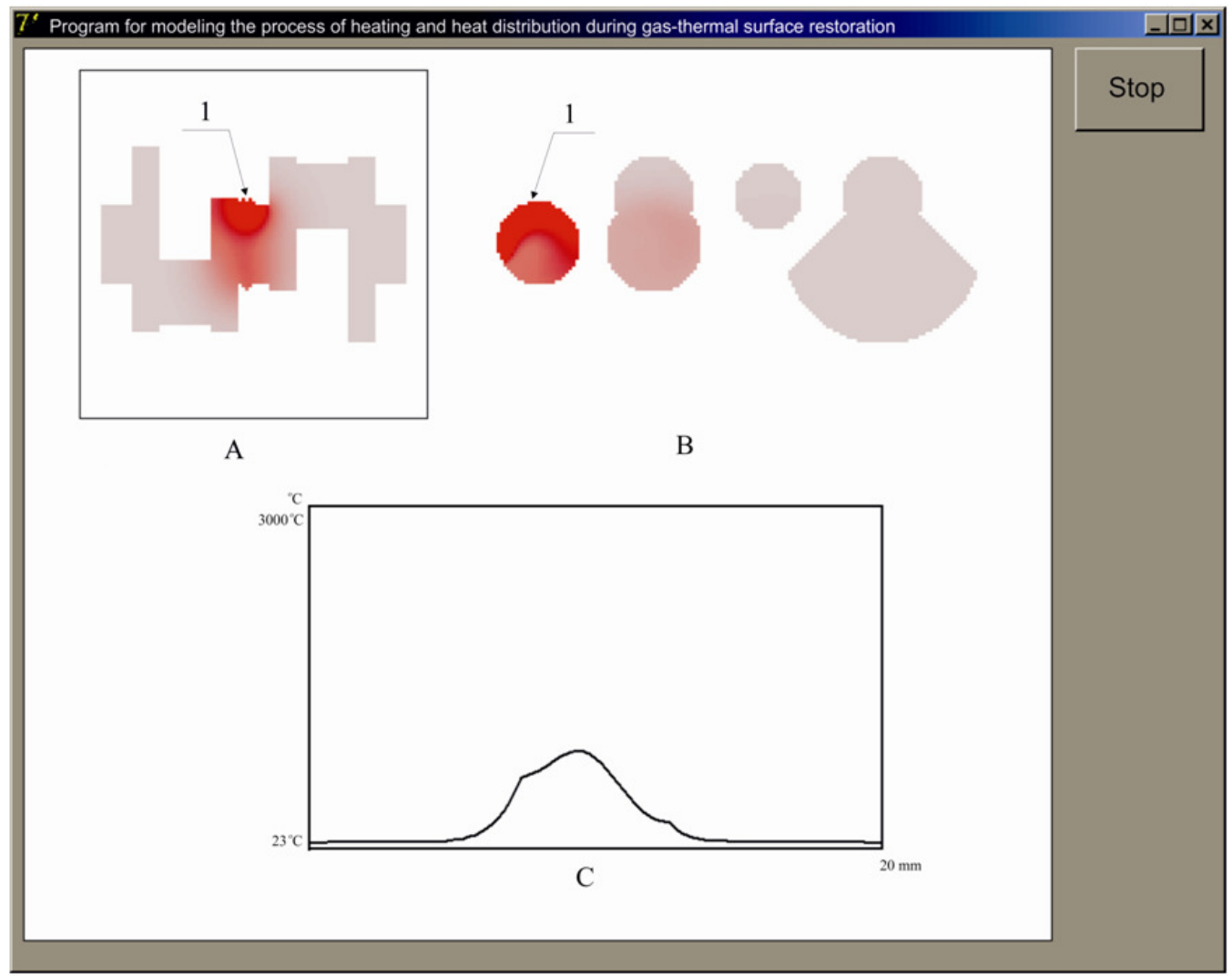

Fig. 2. Results of computer modeling: A - Cartogram of the longitudinal section of the crankshaft (1 - heating zone); B - Cartogram of the cross section of the crankshaft; C - Diagram of temperature distribution along the axis

In the process of a computer experiment, the gas thermal spraying area makes a helical motion around the crankshaft main neck (Fig. 3). From the beginning of the process of thermal recovery, the surface temperature of the crankshaft neck starts growing. The results are shown for a sufficiently slow rotation of the crankshaft and rather intense heating to reproduce the case of surface overheating (temperature above $570{ }^{\circ} \mathrm{C}=T_{\text {extr }}$, it is marked by a dashed line in the graph) and scale formation on the side of the neck, opposite the heating region.

Temperature fluctuations with amplitude of about $100{ }^{\circ} \mathrm{C}$ compared to the increasing average temperature were detected (Fig. 3). The increase and decrease in temperature are associated with the asymmetric arrangement of the crankshaft cheeks relative to the axis of the main neck and their movement relative to the coating area. In this case, the conditions for heat removal change: the closer the coating area is to the center of the geometric area of the cheek, the higher the heat removal.

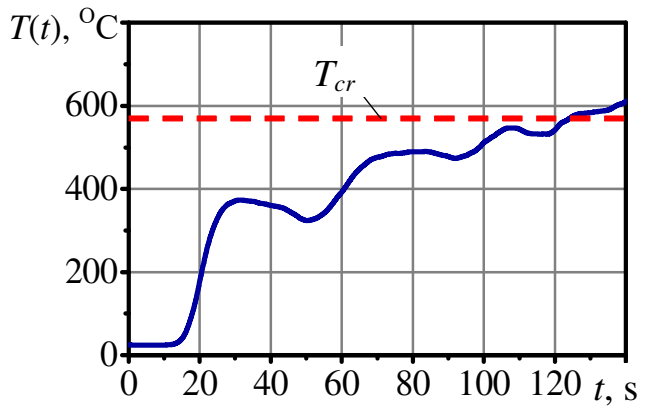

Fig. 3. Dependence of the temperature $T$ of the crankshaft main neck on the side opposite to the heater on the time $t$ during helical coating process 
To confirm the simulation results, experimental studies were conducted on the basis of the laboratory of the Voronezh State Agrarian University named after Emperor Peter I (Fig. 4). The experimental installation for gas thermal recovery was created using a screw-cutting machine (1K62), which ensured the rotation of parts and the movement of the gas burner (GN-2) in longitudinal and transverse direction. Acetylene-oxygen mixture is used in the burner. The self-fluxing metal powder PR-HX17CP4 was transported by oxygen. As the reconditioned part, the crankshaft of the John Deere POWERTECH 6.8L engine was used. Temperature measurements during the restoration of the crankshaft neck were made with a Mastech MS6550B pyrometer. The thickness of the recovered layer was determined by a laser distance meter RDS 205. The distance between the burner and the restored part was regulated within $5-15 \mathrm{~mm}$. The rotation speed of the part is from $5-9 \mathrm{~mm} \cdot \mathrm{s}^{-1}$. The temperature obtained during the experiment differed from the simulation results within 3.0-4.5\%, which allowed us to talk about the adequacy of the model and its compliance with similar studies [7-13; 15-19].

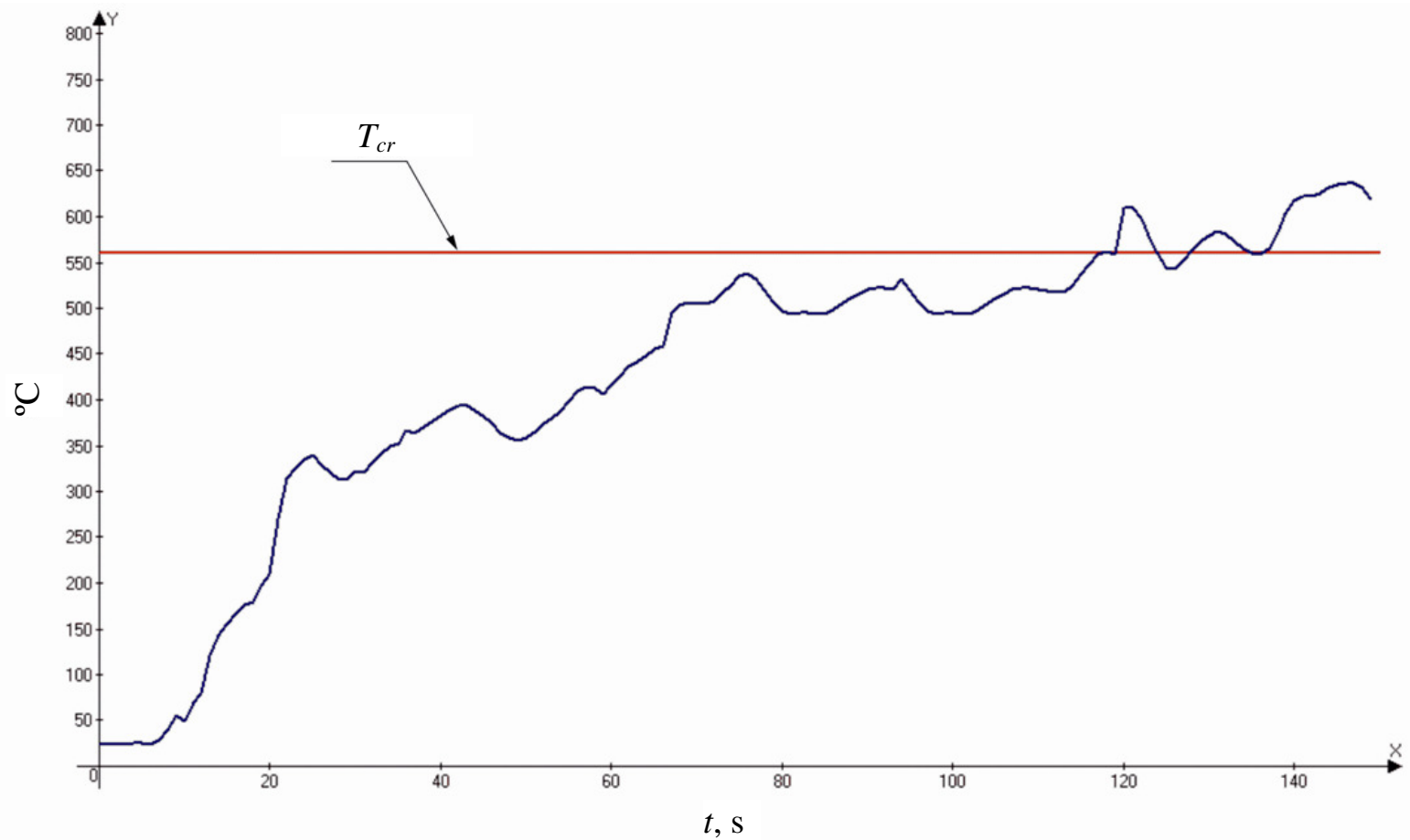

Fig.4. Dependence of the temperature $T$ of the crankshaft main neck on the side opposite to the heater on the time $t$ during the helical coating process, obtained in the experiment

\section{Conclusions}

The mathematical model and the program for calculating the temperature of the surface layer by the volume of the part make it possible to justify the modes of applying the powder material, increase the uniformity of the obtained layer and reduce the cost of subsequent machining of the reconditioned part, and use the data in the control program for flame coating. Application of the model improves the quality of reconditioned parts with a positive economic effect.

\section{References}

[1] Han B., Li M., Wang Y. Microstructure and wear resistance of laser clad Fe-Cr3C2 composite coating on 35CrMo steel. J. Mater. Eng. Perform., vol. 22. 2013, pp. 3749-3754.

[2] Emamian A., Corbin S.F., Khajepour A. Effect of laser cladding process parameters on clad quality and in-situ formed microstructure of Fe-TiC composite coatings. Surf Coat Technol, vol. 205, 2010, pp. 2007-2015.

[3] Wolff S.J., Gan Z., Lin S., Bennett J.L., Yan W., Hyatt G., Ehmann KF., Wagner G.J., Liu W.K., Cao J. Experimentally validated predictions of thermal history and microhardness in laserdeposited Inconel 718 on carbon steel. Additive Manufacturing, vol. 27, 2019, pp. 540-551.

[4] Han L.J., Phatak K.M., Liou F.W. Modeling of laser cladding with powder injection. Metall. Mater. Trans. B, vol. 35, 2004, pp. 1139-1150. 
[5] Han L.J., Phatak K.M., Liou F.W. Modeling of laser deposition and repair process. J. Laser Appl. vol. 17(2), 2005, pp. 89-99.

[6] Hofman J.T., Lange D.F., Pathiraj B. FEM modeling and experimental verification for dilution control in laser cladding. J. Mater. Process. Technol., vol. 211, 2011, pp. 187-196.

[7] Sinel'nikov A.F. The bases of the technology for production and repair of vehicles, machinery, and equipment: student's guidebook. Moscow, 2013, $320 \mathrm{p}$.

[8] Puhov E.V., Astanin V.K., Schegolev I.V. Analysis of the process of restoration of the parts of agricultural machinery operating under bearing pressures // The issues of machinery, equipment, and technology improvement in the agro-industrial complex. Voronezh, 2019, pp. 81-83.

[9] Hasui A., Morigaki O. Weld deposit and evaporation: Translated from Jap. - Moscow, Mashinostroenie, 1985, $240 \mathrm{p}$.

[10] Slinko D.B., Dorohov A.S., Denisov V.A., Lyalyakin V.P. Experience of application of plasmapowder weld for restoration of worn parts of machinery // Engineering technology, 2019, no3, pp. 32-37.

[11] Kolomeychenko A.V. The procedure for improving the longevity of the restored and strengthened microarc oxidated parts // The works of GOSNITI, 2011, vol. 107, no 2, pp. 98-101.

[12] Lebedev A.T., Zaharin A.V., Lebedev P.A., Magomedov R.A., Pavlyuk R.V., Levedev K.A. The study of the welded layers with various concentration of alloying elements // Urgent issues of scientific and technical progress in agro-industrial complex: Proc. conf. Agrouniversal - 2013 and Resource and energy saving in agro-industrial complex. Alternative fuels. - Stavropol, 2013, pp. 261-264.

[13]Zhachkin S.Ju., Sharifullin S.N., Pen'kov N.A., Zavrazhnov A.I. Simulating the kinematic parameters of sedimentation of composite galvanic coatings for restoration of the agricultural machinery parts // Innovative engineering technologies, equipment, and materials - 2018: Proc. Conf. - Kazan', 2018, pp. 267-271.

[14] Gradov V.M., Ovechkin G.V., Ovechkin P.V., Rudakov I.V. Computer modelling: student's guidebook. Moscow: KURS: INFRA-M, 2018. — $264 \mathrm{pp}$.

[15]Gan Z., Gang Y., He X., Li S. 2017b Numerical simulation of thermal behavior and multicomponent mass transfer in direct laser deposition of Co-base alloy on steel. Int J Heat Mass Transfer vol. 104, 2017, pp.28-38.

[16] Yan W., Ge W., Smith J., Lin S., Kafka O.L., Lin F., Liu W.K. 2016 Multi-scale modeling of electron beam melting of functionally graded materials. Acta Mater vol. 115, 2016, pp. 403-412.

[17] Ma M., Wang, Z., Zeng X. A comparison on metallurgical behaviors of 316L stainless steel by selective laser melting and laser cladding deposition. Mater Sci Eng, A, vol. 685, 2017, pp. 265273.

[18] Hu S. Y., Liao J. J., Kang Y. Wear of Flame-Sprayed Ni-Cr-B-Si Powder Coating on Journal for Seal Contact. Proceedings of International conference "Mechanics and Mechatronics Research" October 03, 2016, pp. 6.

[19] Hoking M., Wasantasri V., Sidki P. Metal and ceramic coatings: Production, features, and uses: Translated from Eng. Moscow, Mir, 2000, 518 p. 